\section{UJMM

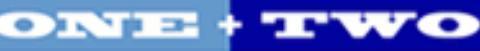

Volume 3 | 2011 Spring

\section{Undergraduate Journal of Mathematical}

Modeling: One + Two

Article 8

2011

\title{
Pallet Physics
}

Lauren Woodbridge

University of South Florida

Advisors:

Arcadii Grinshpan, Mathematics and Statistics

Colt Russelo, Publix Supermarkets: Customer Service

Problem Suggested By: Lauren Woodbridge

Follow this and additional works at: https://digitalcommons.usf.edu/ujmm

Part of the Mathematics Commons

UJMM is an open access journal, free to authors and readers, and relies on your support:

Donate Now

\section{Recommended Citation}

Woodbridge, Lauren (2011) "Pallet Physics," Undergraduate Journal of Mathematical Modeling: One + Two: Vol. 3: Iss. 2, Article 8.

DOI: http://dx.doi.org/10.5038/2326-3652.3.2.8

Available at: https://digitalcommons.usf.edu/ujmm/vol3/iss2/8 


\title{
Pallet Physics
}

\begin{abstract}
This project explores whether it is safe to unload a $907 \mathrm{~kg}$ pallet from a supply truck with a bed $1.5 \mathrm{~m}$ off the ground by sliding it down a metal ramp. First we calculated the critical angle for which the pallet would overcome the friction of the wood on the metal and begin to slide. Next we calculated velocity of the pallet as it reaches the bottom of the ramp. Finally we calculate the distance the pallet travels on the concrete after leaving the ramp. Based on these calculations of acceleration, velocity, and displacement, we conclude that it would not be safe to unload the truck in this manner.
\end{abstract}

\section{Keywords}

Workplace Safety, Frictional Forces, Ramp

Creative Commons License

(c) (i) (3)

This work is licensed under a Creative Commons Attribution-Noncommercial-Share Alike 4.0 License. 


\section{TABLE OF CONTENTS}

Problem Statement

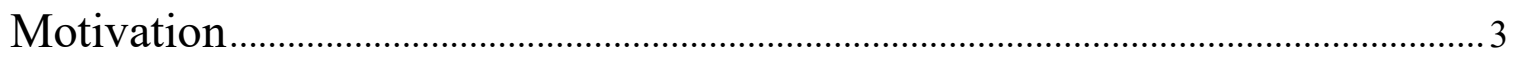

Mathematical Description and Solution Approach .................................................

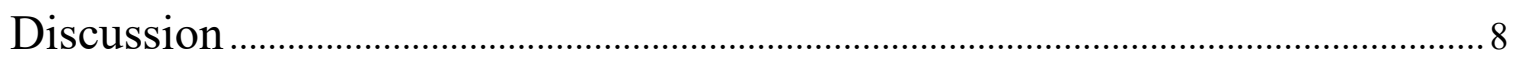

Conclusion and Recommendations ....................................................................

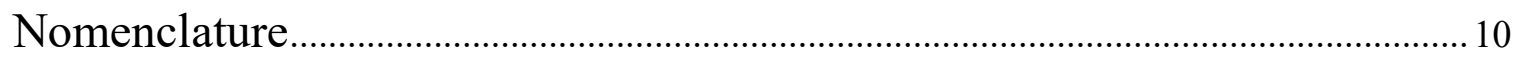

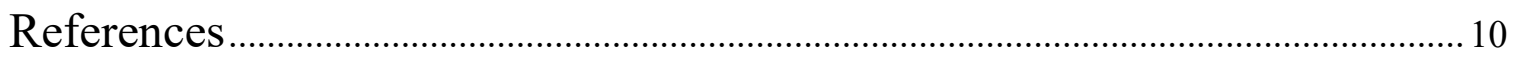




\section{PROBLEM STATEMENT}

In the event of machinery breakdown, is it possible to unload a $907 \mathrm{~kg}$ warehouse pallet from a delivery truck whose trailer stands $1.5 \mathrm{~m}$ off the ground by sliding it down a metal ramp? If it is possible, is it safe for a workplace environment?

\section{MOTIVATION}

Safety is a part of engineering that should never be overlooked. Engineers have designed machines that pick up and move crates safely without endangering the operator or merchandise. However, what happens if these machines breaks down and there is no replacement? Will it be possible to move the crates out of the truck safely, or at all? Publix and other retailers regularly encounter such problems.

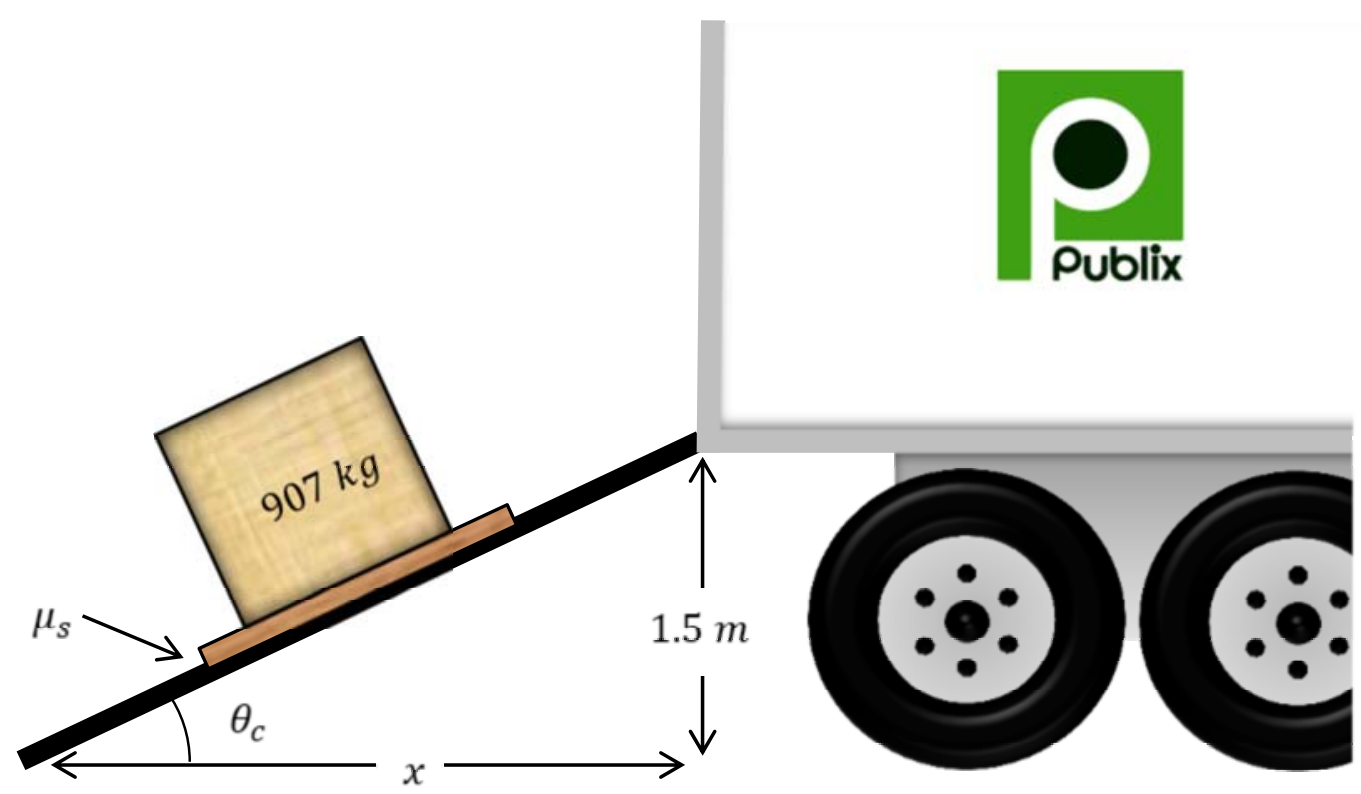

Figure 1: Sliding a $907 \mathrm{~kg}$ pallet down a ramp from the back of a Publix delivery truck. 


\section{MATHEMATICAL DESCRIPTION AND SOLUTION APPROACH}

We shall approach the problem by first finding the critical angle for which a 2,000 lbs wooden pallet will begin to slide on a metal ramp. Next we will calculate the velocity of the pallet as it reaches the bottom of the ramp. Finally we will compute how far the pallet will slide on the concrete after it leaves the ramp.

Critical Angle. Let $\theta_{c}$. be the critical angle where the load overcomes the friction between the ramp and pallet and begins to slide. This occurs when the force of friction $F_{f}$ equals the force pushing the pallet parallel to the ramp $F_{p}$. In other words, for a ramp with angle $\theta_{c}$,

$$
F_{p}=F_{f}
$$

The force of friction can be calculated as the force pressing the pallet to ramp $F_{N}$ multiplied by the static coefficient of friction between the pallet and the ramp, i.e.,

$$
F_{f}=\mu_{s} F_{n}
$$

and from (1) we have

$$
\mu_{s}=\frac{F_{p}}{F_{n}}=\tan \theta_{c}
$$

as seen in Figure 2. The estimated static coefficient of friction between the wood and metal ramp is $\mu_{s}=0.5$ (Coefficient of Friction Reference Table) so

$$
\theta_{c}=\tan ^{-1} \frac{1}{2} \approx 26.6^{\circ}
$$

Given that the height of the truck is $1.5 \mathrm{~m}$, the distance from the truck to the end of the ramp is

$$
x=\frac{1.5 m}{\tan \left(\tan ^{-1} \frac{1}{2}\right)}=3.0 \mathrm{~m}
$$




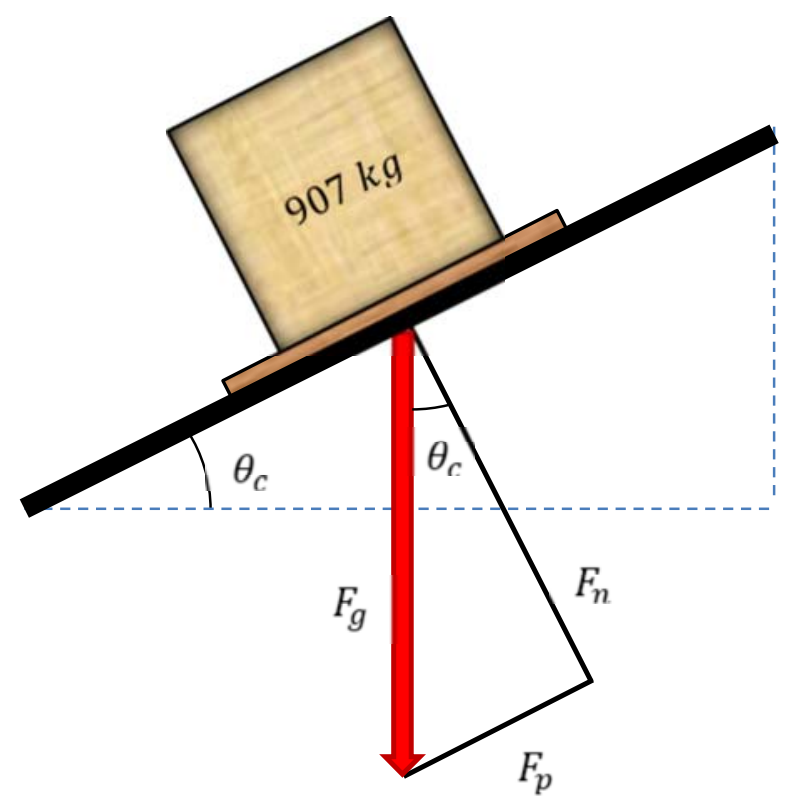

Figure 2: Forces acting on the pallet as it slides down the ramp.

The force of gravity pulling the pallet towards the Earth, $F_{g}$, can be calculated by Newton's second law of motion, i.e.,

$$
F_{g}=m g=(907.18 \mathrm{~kg})\left(9.81 \frac{\mathrm{m}}{\mathrm{s}^{2}}\right)=8,896.44 \mathrm{~N}
$$

From (4), (6), and the fact that

$$
\sin \theta_{c}=\frac{F_{p}}{F_{g}}
$$

we calculate that

$$
F_{p}=F_{g} \sin \theta_{c}=(8,896.44 N)\left(\frac{1}{\sqrt{5}}\right)=3,978.61 N
$$

Similarly, $\cos \theta_{c}=\frac{F_{n}}{F_{g}}$ and

$$
F_{n}=F_{g} \cos \theta_{c}=(8,896.44 N)\left(\frac{2}{\sqrt{5}}\right)=7,957.22 N .
$$


Velocity Leaving the Ramp. Next we can find the velocity of the pallet as it reaches the bottom of the ramp. Once the pallet begins to move we evaluate the frictional force using the kinetic coefficient of friction rather than the static coefficient. Since the static coefficient of friction is usually higher than the kinetic coefficient of friction, we estimate the kinetic coefficient of friction to be $\mu_{k}=0.4$. As a result, the frictional force $F_{f}$ changes to

$$
F_{f}=\mu_{k} F_{n}=(0.4)(7,957.22 N)=3,182.89 N
$$

so the net downward force parallel to the ramp is

$$
F_{n e t}=F_{p}-F_{f}=3,978.61 \mathrm{~N}-3,182.89 \mathrm{~N}=795.72 \mathrm{~N}
$$

From this we may use Newton's second law of motion to calculate the acceleration of the pallet due to gravity as

$$
a(t)=\frac{F_{n e t}}{m}=\frac{795.72 \mathrm{~N}}{907.18 \mathrm{~kg}}=0.877 \frac{\mathrm{m}}{\mathrm{s}^{2}}
$$

Hence, the velocity of the pallet at time $t$ is given by

$$
v(t)=\int_{0}^{t} a(x) d x=0.877 t
$$

and the distance the pallet has traveled along the ramp is

$$
d(t)=\int_{0}^{t} v(x) d x=0.439 t^{2}
$$

From the Pythagorean Theorem, we know that the length of the ramp is $\sqrt{(1.5)^{2}+(3.0)^{2}}=$ $3.35 \mathrm{~m}$ and at the bottom of the ramp

$$
d(t)=0.439 t^{2}=3.35 \quad \Rightarrow \quad t=2.77 \mathrm{~s} .
$$


This means that the velocity of the pallet by the time it gets to the bottom of the ramp is $v(2.77)=2.43 \frac{m}{s}$

Distance Traveled on Concrete. Now we want to know how far the pallet slides once it leaves the ramp. From (Coefficient of Friction Reference Table) we see that the kinetic coefficient of friction between wood and concrete is $\mu_{c o n}=0.6$. Because the pallet is now on a level surface, the normal force $F_{n}$ is equal to the gravitational force $F_{g}$ so

$$
F_{f}=\mu_{c o n} F_{n}=(0.6)(8,896.44 N)=5,337.87 N
$$

and the kinetic friction is decelerating the pallet according to

$$
a(t)=\frac{-F_{f}}{m}=\frac{-5337.87 \mathrm{~N}}{907.18 \mathrm{~kg}}=-5.89 \mathrm{~m} / \mathrm{s}^{2} .
$$

Given that that the velocity is initially $v_{\text {con }}=2.43 \frac{\mathrm{m}}{\mathrm{s}}$ at the bottom of the ramp, we compute the velocity on the concrete as

$$
v(t)=\int_{t_{0}}^{t} a(x) d x=2.43-5.89 t
$$

The pallet comes to rest when $v(t)=0$, which occurs at $t=0.41 \mathrm{~s}$. By integrating (18) with respect to time $t$ and using the fact that the displacement is initially zero, we can compute the total displacement of the pallet from the end of the ramp as

$$
d(t)=\int_{t_{0}}^{t} v(x) d x=-2.93 t^{2}+2.43 t
$$

meaning that the pallet came to rest on the concrete $d(0.41)=0.5 \mathrm{~m}$ beyond the ramp. 


\section{DISCUSSION}

Upon examination, one can tell that this situation would be a dangerous one. The pallet is so heavy that it reaches a high speed very quickly, assuming that the ramp is strong enough to

hold it. The pallet would reach a speed of $2.43 \frac{\mathrm{m}}{\mathrm{s}}(\approx 5.43 \mathrm{mph})$, and then continue an additional half meter past the ramp (again assuming that it wouldn't crash and break in the process.)

Before calculations the idea of unloading a supply truck by sliding the pallets down a ramp seemed plausible when the fork lifts and pallet jacks brake. Some straightforward calculations reveal that this method would be risky for employees and merchandise alike. Throughout the analysis it was assumed that pallet would slide smoothly down the ramp and successfully transition onto the concrete. In reality, a pallet is likely to crash or topple unless its weight is significantly decreased. Both the product and employees are in great danger to be hurt if this process is used.

However, this project showed the importance of analyzing ideas mathematically before testing them physically. In the Publix working environment, there are many rules and limitations for machinery and structures. Engineers used similar equations and processes to establish a safe working environment and keep everybody healthy.

\section{CONCLUSION AND RECOMMENDATIONS}

Based on our analysis, warehouse pallets should be left in the supply truck or on the rack when there is no machine to carry them. Even with a moderate coefficient of static and kinetic 
friction, the pallet would reach $2.43 \frac{\mathrm{m}}{\mathrm{s}}$ which is dangerously fast for something that weighs $907 \mathrm{~kg}$. Because the final velocity on the ramp is the same as the initial velocity for the ground, the pallet would slide on the concrete for $0.41 \mathrm{~s}$ and travel $0.5 \mathrm{~m}$ past the ramp once it reached the bottom. While this may not be extreme for a small box of books, this is a significant speed for a pallet stacked with cans of green beans.

This project would benefit from physical experimentation. The coefficients of friction used in this project were estimations based on prior experience, the Internet, and various physics handbooks. Measuring the coefficient of static friction between specific types of wood with various metals would yield much more accurate results. Further, this analysis did not consider the length of the ramp that Publix stores and warehouses have access to.

Finally, a number of similar situations should be further explored. Perhaps the machines broke down overnight when the pallets were already within the aisles. - do the pallets have potential to be pushed back to storage by morning, and how many workers would be needed to collectively move such a pallet? 


\section{NOMENCLATURE}

\begin{tabular}{|c|c|c|}
\hline Symbol & Description & Units \\
\hline$m$ & Mass & $k g$ \\
\hline$g$ & Acceleration due to gravity & $9.81 \mathrm{~m} / \mathrm{s}^{2}$ \\
\hline$F_{f}$ & Friction force & $N$ \\
\hline$F_{p}$ & Force on pallet parallel to the ramp/concrete & $N$ \\
\hline$F_{g}$ & Force due to acceleration of gravity & $N$ \\
\hline$F_{n}$ & Normal force & $N$ \\
\hline$\mu_{s}$ & Coefficient of static friction (wood and metal) & 0.5 \\
\hline$\mu_{k}$ & Coefficient of kinetic friction (wood and metal) & 0.4 \\
\hline$\mu_{c o n}$ & Coefficient of kinetic friction (wood and concrete) & 0.6 \\
\hline$d$ & Displacement & $m$ \\
\hline$v$ & Velocity & $m / s$ \\
\hline$a$ & Acceleration & $m / s^{2}$ \\
\hline$t$ & Time & $s$ \\
\hline$x$ & Length from the truck to the end of the ramp & $m$ \\
\hline
\end{tabular}

\section{REFERENCES}

Baumeister, Theodore, Eugene Avallone and Theodore Baumeister III. Mark's Standard Handbook for Mechanical Engineering. New York: Random, 1979.

"Coefficient of Friction Reference Table." n.d. Engineers Handbook. 8 May 2011

$<$ http://www.engineershandbook.com/Tables/frictioncoefficients.htm>.

Larson, Ron, Robert Hostetler and Bruce Edwards. Calculus. 8th Edition. Boston, MA: Houghton Mifflin Company, 2005.

Serway, Raymond and John Jewett. Physics for Scientists and Engineers: Eighth Edition. Ohio: Mason, 2009. 